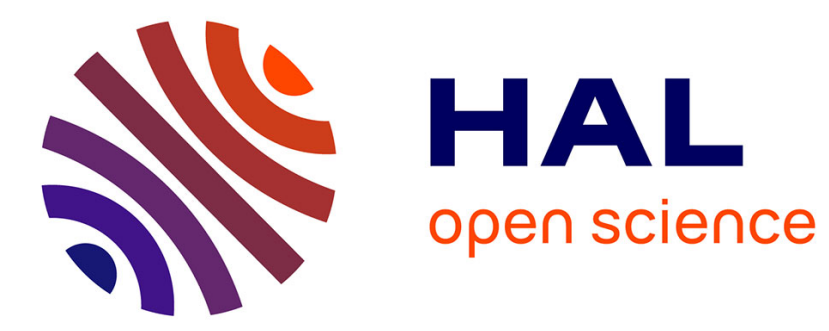

\title{
Spectroscopy of Mn4+ doped gadolinium gallium garnet in high magnetic field
}

\author{
A. Suchocki, M. Potemski, A. Brenier, C. Pedrini, G. Boulon
}

\section{To cite this version:}

A. Suchocki, M. Potemski, A. Brenier, C. Pedrini, G. Boulon. Spectroscopy of Mn4+ doped gadolinium gallium garnet in high magnetic field. Journal de Physique IV Proceedings, 1994, 04 (C4), pp.C4-337C4-340. 10.1051/jp4:1994480 . jpa-00252743

\section{HAL Id: jpa-00252743 https://hal.science/jpa-00252743}

Submitted on 1 Jan 1994

HAL is a multi-disciplinary open access archive for the deposit and dissemination of scientific research documents, whether they are published or not. The documents may come from teaching and research institutions in France or abroad, or from public or private research centers.
L'archive ouverte pluridisciplinaire HAL, est destinée au dépôt et à la diffusion de documents scientifiques de niveau recherche, publiés ou non, émanant des établissements d'enseignement et de recherche français ou étrangers, des laboratoires publics ou privés. 


\title{
Spectroscopy of $\mathrm{Mn}^{4+}$ doped gadolinium gallium garnet in high magnetic field
}

\author{
A. SUCHOCKI, M. POTEMSKI* A. BRENIER ${ }^{* *}$, C. PEDRINI** and G. BOULON** \\ Institute of Physics, Polish Academy of Sciences, Al. Lotnikow 32/46, 02-668 Warszawa, Poland \\ * High Magnetic Field Laboratory, MPIFKF \& CNRS, 25 av. des Martyrs, BP. 166, 38042 Grenoble cedex \\ 9, France \\ ${ }^{* *}$ Laboratoire de Physico-Chimie des Matériaux Luminescents, Université Claude Bernard Lyon I, 43 bd \\ du 11 Novembre 1918, 69622 Villeurbanne, France
}

\begin{abstract}
A B S T R A C T
The R-lines of the $\mathrm{Mn}^{4+}$ fluorescence, associated with ${ }^{2} \mathrm{E} \rightarrow$ ${ }^{4} \mathrm{~A}_{2}$ transitions in gadolinium gallium garnet exhibits large broadening as compared with other ions with $\mathrm{d}^{3}$ shell. The laser excitation and fluorescence spectra without magnetic field show that this is partially inhomogeneous broadening related to presence of charge-compensating $\mathrm{Ca}^{2}+$ ions. Remaining part of the broadening is due to antiferromagnetic exchange interaction between $\mathrm{Mn}^{4+}$ and surrounding them six $\mathrm{Gd}^{3+}$ ions. The high magnetic field up to $20 \mathrm{~T}$ has been used to resolve the spectra broadened by spin-spin interaction. The estimated value of the spin-spin exchange constant is equal to $J=1.9 \mathrm{~cm}^{-1}$.
\end{abstract}

\section{Introduction}

The gadolinium gallium garnet (GGG) with various dopants has been studied as interesting system for solid-state laser application. $\mathrm{Mn}^{4+}$ dopant can be either an active lasing center or a codopant facilitating efficient energy transfer to other ions, emitting in the near-infrared. To obtain manganese ions in the 4+ state it was necessary to codope the GGG crystal with charge-compensating $\mathrm{Ca}^{2+}$ ions. It has been known that in GGG crystal doped with $\mathrm{Cr}^{3+}$, where charge compensation is not necessary, there are at least four different chromium centers. Codoping with additional ion is likely to increase the number of centers. Indeed, in our previous paper [1] we have shown that various manganese centers do exist in such a crystal. Different manganese centers with close charge compensation and without close charge compensation can be identified in the crystal. Moreover, the large broadening of the R-lines and very large "Stokes" shift between the excitation and emission spectra were noticed in the GGG: $\left(\mathrm{Mn}^{4+}, \mathrm{Ca}^{2+}\right)$ crystal. These effects were assigned to low-energy host excitations of probably magnetic origin.

The effect of magnetic interaction of chromium dopant with surrounding gadolinium ions has been discussed by Murphy and Ohlmann in case of $\mathrm{GdAlO}_{3}$ [2] and recently by Monteil and co-workers in GGG crystal [3] and Yamaga and co-workers in GSAG [4]. In this paper we report further 
laser excitation and fluorescence studies of $\mathrm{GGG}:\left(\mathrm{Mn}^{4+}, \mathrm{Ca}^{2+}\right)$ crystal in high magnetic fields.

\section{Experimental.}

In this paper we restrict our studies to $\mathrm{Mn}^{4+}$ centers without close compensation by $\mathrm{Ca}^{2+}$ ions. At zero magnetic field the fluorescence attributed to these centers is around $663.5 \mathrm{~nm}$ at $2.2 \mathrm{~K}$. The spectrum consists of two major peaks, strongly overlapped on each other [1]. The positions of the peaks move if excitation wavelength is shifted. The results of such fluorescence line narrowing measurements are presented in Fig. 1. This proves that the line attributed to manganese centers without close compensation is broadened inhomogeneously. The charge-compensating calcium ions are the most probable source of broadening in the crystal, even if they are located not as the closest neighbors of the luminescent $\mathrm{Mn}^{4+}$ ions.

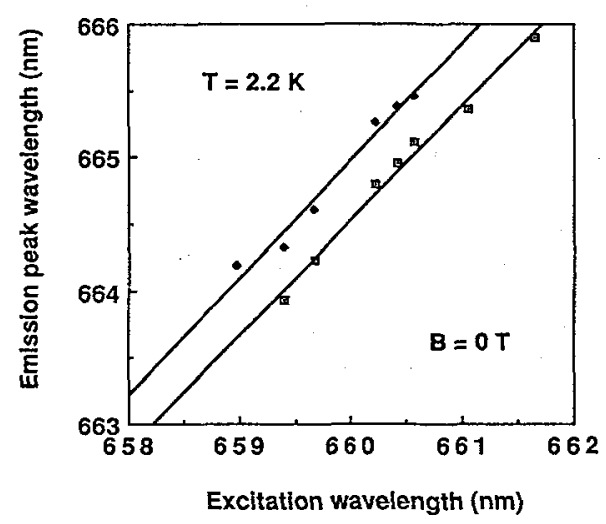

Fig. 1. Position of the two main peaks in the fluorescence spectrum at zero magnetic field at $2.2 \mathrm{~K}$ as a function of laser excitation wavelength.

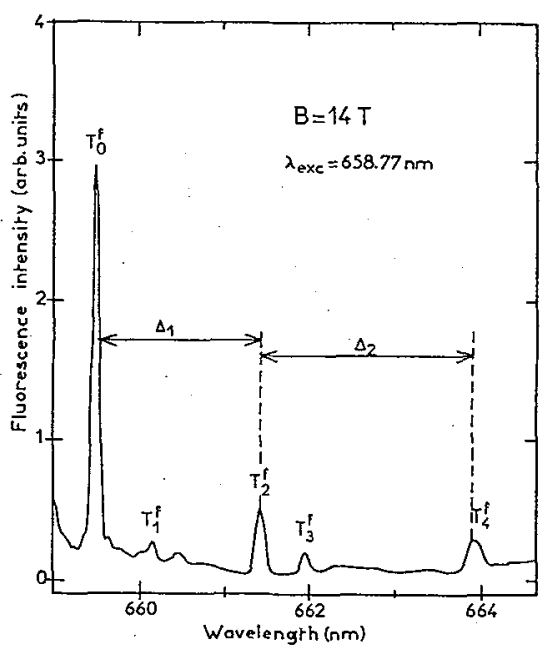

Fig. 2. Fluorescence spectrum at $\mathrm{B}=14 \mathrm{~T}$, excited by $658.77 \mathrm{~nm}$ laser light at $2.2 \mathrm{~K}$. The transitions to Zeeman sublevels of the ground state are marked on the graph.

Inhomogeneous broadening of the $R$ lines makes the spectra much more complicated and the individual component of the broad line can be resolved only in high magnetic fields. When magnetic field is applied to the crystal (along [111] axis, in Faraday configuration) the fluorescence spectrum initially split in four broad lines at relatively low magnetic fields up to $5 \mathrm{~T}$. Above that field additional splitting of each line is observed and individual classes of manganese centers of previously very broad line are recorded. The lines are still relatively broad (approx. $4 \mathrm{~cm}^{-1}$ FWHM). The typical 
spectrum, excited at first higher energy state from the main fluorescence peak is shown in Fig. 2. The spectrum consists of several peaks of different intensity. There are the same states in the excitation spectra of the fluorescence peaks with lower energy as in the excitation spectrum of the main fluorescence peak. The similar spectra can be obtained for various excitation wavelengths, which is a fingerprint of inhomogeneous broadening, now well resolved. The distances between the main three lines, marked on the graph and the distance from the first peak in the excitation spectrum are dependent on the magnetic field. The dependencies are presented in Fig.3.

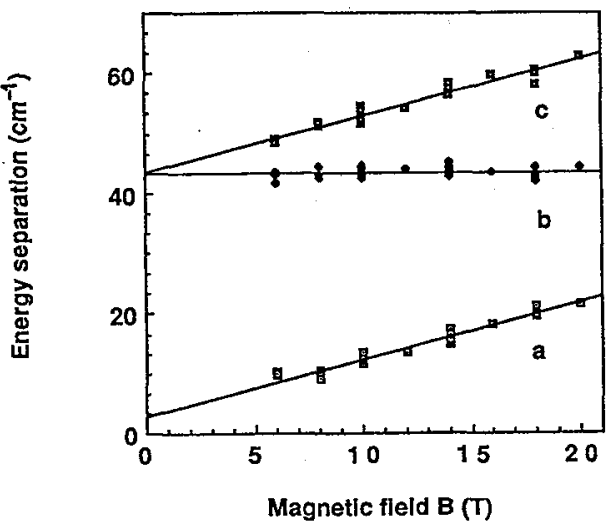

Fig. 3. The magnetic field dependence of the energy separation between the maximum of the excitation line and first fluorescence line, corresponding to energy separation between $\mathrm{T}^{\mathrm{e}}$ and $\mathrm{T}^{\mathrm{f}} 0$ transitions (a); energy separation between $\mathrm{T}^{\mathrm{f}_{0}}$ and $\mathrm{T}_{2}$ transitions (b); and energy separation between $T_{2}$ and $\mathrm{T}_{4}$ transitions (c), recorded for various excitation wavelength.

\section{Discussion}

The theory, originated from Murphy and Ohlmann [2], assumes isotropic antiferromagnetic interaction between central $\mathrm{Mn}^{4+}$ ion and six $\mathrm{Gd}^{3+}$ ions. In presence of external magnetic field $B$ the interaction is described by the following Hamiltonian:

$$
H_{t}=-J S_{M n} \cdot S+g_{M n} \mu_{B} S_{M n} B+g_{G d} \mu_{B} S B=-J S_{M n} \cdot S+g 0 \mu_{B} S B
$$

where $J$ is the exchange integral, $S_{M n}, S$ and $S$ are the spin of $\mathrm{Mn}^{4+}$ ion, total spin of six $\mathrm{Gd}^{3+}$ ions and total spin of the interacting system, respectively, $\mathrm{g}_{\mathrm{Mn}}=\mathrm{gGd}_{\mathrm{G}}=\mathrm{g}_{0} \approx 2$ and $\mu_{\mathrm{B}}$ is Bohr magneton. The expectation values of the Hamiltonian without magnetic field are equal to:

$$
\mathrm{E}_{\exp }=-(J / 2) \cdot\left[S(S+1)-\mathrm{S}(\mathrm{S}+1)-\mathrm{S}_{\mathrm{Mn}}\left(\mathrm{S}_{\mathrm{Mn}}+1\right)\right]
$$

The ground state and excited states of the system are split into a quasicontinuum band of exchange coupled sublevels having different total spin quantum number $S$. These levels are additionally split by the Zeeman interaction if external magnetic field in applied. At $2.2 \mathrm{~K}$ fluorescence occurs only between first excited Zeeman sub-level and certain Zeeman sub-levels of the ground state with magnetic number which differs by $0, \pm 1$. 
Additionally, the total spin of gadolinium ions is conserved. Therefore the transitions occur between the following levels:

$$
\begin{aligned}
& \text { in excitation: } \\
& \text { is }=22.5 ; \mathrm{MS}=-22.5 ; \mathrm{S}=21 ; \mathrm{S}_{\mathrm{Mn}}\left({ }^{4} \mathrm{~A}_{2}\right)=3 / 2>\rightarrow \\
& \text { iS }=21.5 ; \mathrm{MS}=-21.5 ; \mathrm{S}=21 ; \mathrm{SMn}_{\mathrm{Mn}}\left({ }^{2} \mathrm{E}\right)=1 / 2>: \mathrm{T}^{\mathrm{e}} \\
& \text { IS }=21.5 ; \mathrm{MS}=-21.5 ; \mathrm{S}=21 ; \mathrm{S}_{\mathrm{Mn}}(2 \mathrm{E})=1 / 2>\quad \rightarrow \\
& I S=22.5 ; \mathrm{MS}=-21.5 ; \mathrm{S}=21 ; \mathrm{S}_{\mathrm{Mn}}\left({ }^{4} \mathrm{~A}_{2}\right)=3 / 2>: \mathrm{T}^{\mathrm{f}_{0}} \\
& \mid S=22.5 ; \mathrm{MS}=-20.5 ; \mathrm{S}=21 ; \mathrm{S}_{\mathrm{Mn}}\left({ }^{4} \mathrm{~A}_{2}\right)=3 / 2>: \mathrm{T}^{\mathrm{f}} \\
& \mid S=21.5 ; \mathrm{MS}=-21.5 ; \mathrm{S}=21 ; \mathrm{SMn}\left({ }^{4} \mathrm{~A}_{2}\right)=3 / 2>: \mathrm{T}_{2} \\
& \text { IS }=21.5 ; \mathrm{MS}=-20.5 ; \mathrm{S}=21 ; \mathrm{S}_{\mathrm{Mn}}\left({ }^{4} \mathrm{~A}_{2}\right)=3 / 2>: \mathrm{T}_{3} \\
& I S=20.5 ; \mathrm{MS}_{S}=-20.5 ; \mathrm{S}=21 ; \mathrm{SMn}_{\mathrm{Mn}}\left({ }^{4} \mathrm{~A}_{2}\right)=3 / 2>: \mathrm{T}^{\mathrm{f}_{4}}
\end{aligned}
$$

All these transitions can be identified in our spectra. The other transitions are forbidden.

The energy separations between these transition are equal to:

$$
\begin{aligned}
& \Delta_{0}=\mathrm{E}\left(\mathrm{T}^{\mathrm{e}}\right)-\mathrm{E}\left(\mathrm{T}^{\mathrm{f}_{0}}\right)=2 \mu_{\mathrm{B}} \mathrm{B} \\
& E\left(T_{0}^{f}\right)-E\left(T^{f}{ }_{1}\right)=2 \mu_{B} B \\
& \Delta_{1}=E\left(T^{f_{0}}\right)-E\left(T_{2}\right)=22.5 J \\
& E\left(T^{f_{2}}\right)-E\left(T^{f_{3}}\right)=2 \mu_{B} B \\
& \Delta_{2}=\mathrm{E}\left(\mathrm{T}^{\mathrm{f}} 2\right)-\mathrm{E}\left(\mathrm{T}_{4}\right)=21.5 J+2 \mu_{\mathrm{B}} \mathrm{B}
\end{aligned}
$$

The value of $\boldsymbol{J}$ estimated from the last equations and results presented in Fig 3 is equal to $1.9 \mathrm{~cm}^{-1}$, approximately. This value is relatively large, similar to that obtained by Murphy and Ohlmann for $\mathrm{GdAlO}_{3}: \mathrm{Cr}^{3+}$ [2]. Yamaga et al. obtained value of $\mathrm{J}=0.25-0.33 \mathrm{~cm}^{-1}$ for GSAG: $\mathrm{Cr}^{3+}$ [4]. The full report of these studies will be published in a following paper.

Acknowledgments:

A. Suchocki has been supported by the grant CIPA3510PL921612 of the Commission of the European Communities.

\section{References:}

1. A. Brenier, A. Suchocki, C. Pedrini, C. Madej and G. Boulon, Phys. Rev. B. 46, 3219 (1992).

2. J. Murphy and R.C. Ohlmann, in Optical Properties of Ions in Crystals, ed. H.M. Crosswhite and H.W. Moos (New York, Wiley 1967 ), p. 239.

3. A, Monteil, M. Ferrari, F. Rossi, Phys. Rev. B 43, 3646 (1991).

4. Y. Gao, M. Yamaga, C. Ogihara, K.P. O'Donnell and B. Henderson, J.Phys.: Condens. Matter 4, 7307 (1992); M. Yamaga, Y. Gao, K.P. O'Donnell and B. Henderson, J. Phys.: Condens. Matter 5, 915 (1993). 